\title{
Estado e burocracia na concepção político-jurídica de E. Pachukanis ${ }^{1}$
}

State and bureaucracy in the political-legal concept of $E$. Pashukanis

Ivan Ivanovitch Makeev²

RESUMO: No presente trabalho, Ivan Ivanovitch Makeev elabora uma compilação das considerações de Pachukanis sobre a questão da burocracia na União Soviética. Nesse sentido, o objeto de investigação é o fenômeno do burocratismo e sua compreensão pelo pensamento soviético inicial. Nós nos encontramos, neste trabalho, com uma série de questões interessantes, tais como a concepção de Pachukanis sobre o direito e o Estado, seu entendimento sobre a conexão entre a burocracia e o capitalismo, sua identificação do processo de burocratização em curso na União Soviética e suas propostas voltadas à reversão desse curso de eventos.

Palavras-chave: Evgeny Bronislavovitch Pachukanis; Estado e burocracia; administração estatal; legalidade; superação do burocratismo.

1 Artigo originalmente publicado como MAKEEV, Ivan Ivanovitch. Государство и бюрократия в политико-правовой концепции Е. Пашуканиса [Estado e burocracia na concepção político-jurídica de E. Pachukanis]. Бизнес в законе: Экономико-юридический журнал [Negócios e lei: periódico jurídico-econômico], Moscou, n. 3, p. 38-41, 2012. Tradução de Pedro Pompeo Pistelli Ferreira (graduado em direito pela Universidade Federal do Paraná).

2 Pós-graduando no departamento de teoria e história do direito e do Estado da Universidade Social Estatal Russa (Российский государственный социальный университет) (texto informado pelo autor em 2012). 
ABSTRACT: In the present work, Ivan Ivanovich Makeev makes a compilation of Pashukanis' assertions about the problem of bureaucracy in the Soviet Union. In that sense, the object of research is the phenomenon of bureaucracy and its interpretation in the early soviet political and legal thought. We are faced, in this work, with a series of interesting questions, as such as Pashukanis' conception of law and the state, his understanding about the connection between bureaucracy and capitalism, his recognition of the process of bureaucratization that was happening in the Soviet Union and his propositions aimed to suppress that course of events.

Keywords: Evgeny Bronislavovich Pashukanis, government and bureaucracy, state and bureaucracy, public administration, the legality, overcoming bureaucracy.

Recentemente, tanto nas universidades jurídicas russas quanto estrangeiras nota-se [наблюдаться, nablyudat'sya] um interesse no direito e nas concepções jurídicas do período inicial do governo soviético. ${ }^{3}$

Um lugar especial entre os teóricos do direito soviético é ocupado pelo representante da escola crítica e sociológica do direito, autor de mais de 100 trabalhos sobre filosofia do direito, teoria geral do direito e do Estado, história das doutrinas políticas e história do Estado e do direito: Evgeny Bronislavovitch Pachukanis (1891-1937). Pachukanis é o único marxista e jurista soviético que alcançou um incomum e amplo reconhecimento científico para além das fronteiras da URSS. Hoje, no Ocidente, praticamente todos os seus mais importantes trabalhos já foram traduzidos. Em universidades jurídicas de prestígio são dados cursos de especialização sobre sua teoria do direito e são preparadas dezenas de publicações dedicadas à análise das concepções desse jurista.

3 Cf. SOLOMKO, 2011, p.124-127; PROTOPOPOV, 2007; BONDARENKO, 2010; TIKHONOVSKY, 2009; KHOTCHOYAN, 2008; PETUKHOVA, 2012; HEAD, 2009; BOWRING, [2006]. 
Entre os teóricos soviéticos do direito, Pachukanis foi um dos primeiros a prestar atenção na importância das investigações sobre os problemas da administração, do aparato estatal, das questões sobre o papel da burocracia no Estado, sobre os mecanismos jurídicos de funcionamento ótimo dos institutos estatais, sobre os caminhos de superação da burocratização do Estado, sobre a democracia burguesa e a proletária, etc.

A concepção mesma de Estado de Pachukanis resulta da ideia de que sem o Estado as classes se destruiriam em um antagonismo encarniçado e arruinariam a sociedade como um todo. "Consequentemente [, em sua opinião,] o Estado aparece quando nenhuma das classes em luta pode conquistar a vitória definitiva. Nesse caso, ocorre uma das duas hipóteses: ou o Estado estabiliza essa relação - então, ele é uma força que se coloca acima das classes [надклассовая сила, nadklassovaya sila], e isso nós não podemos aceitar -, ou ele é resultado da vitória de uma dessas classes, mas, nesse caso, para a sociedade, decai a necessidade do Estado, porque, com a vitória decisiva de uma classe, o equilíbrio é restaurado e a sociedade é salva" (PACHUKANIS, 1980, p. 132). Por trás dessas controvérsias, na opinião do jurista, esconde-se uma questão fundamental: "por que o Estado não permanece como aquilo que ele é, i. e., como a submissão fática de uma parte da população a outra, mas se reveste [принимать, prinimat'] da forma de um poder [властвование, vlastvovanie] estatal oficial [...] por que o aparato de coerção dominante não é criado como um aparato particular da classe dominante, mas se separa desta e se reveste [принимать, prinimat'] da forma de um aparato de poder público impessoal e apartado da sociedade" (PACHUKANIS, 1980, p. 132). A "teoria jurídica da troca de mercadorias" [меновая теория права, menovaya teoriya prava] de Pachukanis joga luz no aspecto jurídico desse paradoxo.

Diferentemente de P. I. Stutchka, que deduz o direito das relações de produção enquanto tais, Pachukanis conecta o direito às relações de troca mercantis. O direito, para ele, é, antes de tudo, um produto das relações de troca. O poder enquanto "vontade geral", enquanto "poder de direito", realiza-se na sociedade burguesa na medida em 
que ela "se apresenta como um mercado" (PACHUKANIS, 1980, p. 135). Ele enfatiza que o valor de troca deixa de ser valor de troca e a mercadoria deixa de ser mercadoria quando a proporção de troca é determinada por uma autoridade e não pelas leis do próprio mercado: "a coerção como ordem de uma pessoa dirigida a outra e apoiada pela força contraria o pré-requisito fundamental das relações entre portadores de mercadorias. Portanto, na sociedade dos proprietários de mercadorias e dentro dos limites do ato de troca, a função da coerção não pode se apresentar como uma função social que não seja abstrata e impessoal" (PACHUKANIS, 1980, p. 135).

Nesse caso, assevera Pachukanis, a coerção já se apresenta como uma coerção que emana de algum sujeito [лицо, litso] abstrato em interesse de todos os participantes da comunidade de conexões [общение, obschenie] jurídica. As funções do Estado como garante do mercado são determinadas pelas demandas do próprio mercado. $\mathrm{O}$ direito surge quando aparecem interesses particulares isolados. Em tal sociedade o poder do homem sobre o homem realiza-se como poder do direito mesmo, como poder de uma norma objetiva e imparcial.

Dessa maneira, a dominação [властвование, vlastvovanie] adquire um "caráter jurídico de publicidade, quando ao lado e independentemente dela surgem relações conectadas com os atos de troca, i.e., relações particulares par excellence [por excelência]. Apresentando-se na qualidade de garante dessas relações, o poder se torna um poder público, que persegue o interesse impessoal da ordem" (PACHUKANIS, 1980, p. 130).

Pachukanis acredita que o capitalismo cria as condições para o florescimento da forma jurídica dos processos sociais, liquidando as conexões parciais, dependências pessoais, privilégios, etc., substituindo-os por relações jurídicas. O Estado enquanto organização da dominação [господство, gospodstvo] de classe não demanda e não permite a interpretação jurídica. Aqui, reina o princípio da conveniência pura [голой целесообразности, goloy tselesoobraznosti]. O poder "como garante das trocas mercantis -- nota o jurista -- não apenas pode ser expresso nos termos do direito, mas apresenta a si mesmo como direito e apenas direito, i.e., funde-se completamente com uma norma 
objetiva abstrata. Por isso toda teoria jurídica do Estado que tenta englobar todas as funções deste é, por essência, inadequada. Elas não podem ser representações [отражение, otrajenie] corretas de todos os fatos da vida estatal, mas propiciam apenas uma representação ideológica, i.e., distorcida, da realidade" (PACHUKANIS, 1980, p. 131).

De acordo com Pachukanis, a dominação de classe tanto em sua forma organizada quanto desorganizada é muito mais ampla do que aquele âmbito que pode ser designado como dominação oficial do poder estatal: a sociedade mercantil cria uma dominação indireta e abstrata [отраженный, otrajennyi] na forma [в виде, v vide] de um poder oficial estatal como força especial que se separou da sociedade (PACHUKANIS, 1980, p. 130 131). Além de sua forma política correspondente, o capital comercial cria junto com ele também a organização burocrática. Consequentemente, o "Estado dos juristas", apesar de seu "caráter ideológico" [диалогичность, ideologitchnost'] corresponde a uma realidade objetiva: "essa realidade, antes de tudo, é o aparato estatal mesmo em seus elementos pessoais e materiais" (PACHUKANIS, 1980, p. 140).

Na opinião de Pachukanis, o aparato estatal é um dos mais poderosos instrumentos de poder. O "Estado de direito", em seu ponto de vista, é, por essência [суть, sut'], uma "miragem" muito vantajosa para a burocracia, porque substitui a ideologia religiosa e oculta das massas o fato da dominação da burocracia burguesa: a ideologia do "Estado de direito" é mais vantajosa do que a religiosa porque ela, apesar de não refletir completamente a realidade objetiva, ainda se baseia nesta. De acordo com Pachukanis, na luta entre diversas forças políticas -classes, partidos e todos os agrupamentos possíveis -- escondem-se as verdadeiras molas propulsoras do mecanismo estatal, portanto em qualquer decisão [постановление, postanovlenie] de um parlamento é possível ver não um ato do Estado, mas uma decisão tomada por um grupo determinado, um punhado de pessoas que detêm motivos individual-egoísticos ou de classe. O jurista atesta que, no Estado burguês, por meio da formação de uma hierarquia espiritual e secular, em primeiro lugar se sobressai a conservação de seus privilégios, a luta contra as classes inferiores [низший, nizshiy] da população e contra 
os combatentes ativos da nova classe que ascende ao poder. Em tais condições o aparato repressivo do Estado começa a jogar um papel cardinal: "o Estado como fator de força [...]: essa é a emenda que a burguesia é forçada a fazer em sua própria teoria e prática do 'Estado de direito'” (PACHUKANIS, 1980, p. 141). E quanto mais instável for a dominação da classe dirigente [правящий, pravyashchiy], ainda mais as concessões passam por "emendas" e mais rapidamente o "Estado de direito" retorna à sombra.

Pachukanis nota que o poder estatal, que defende os interesses de um pequeno grupo de pessoas contra a imensa maioria dos trabaIhadores, está sempre interessado em revestir as instituições estatais e tudo que delas emane de uma auréola de especial solenidade, de grandeza, de quase santidade: os órgãos de poder estatais, em teoria e alegadamente [на словах, na slovakh], reconhecem-se como realizadores e "servidores do povo", tentam inspirar em todos uma estima especial e um medo venerador [почтительный, potchitel'nyi] (PACHUKANIS, 1930a, p. 62-63).

A transição da época do capitalismo industrial para a do capitalismo financeiro, em sua opinião, coloca novas tarefas à frente da administração. A organização estatal conecta-se com as organizações monopolistas do capital financeiro e demanda um novo tipo de funcionário, conectado com os círculos empresariais, bancários e financeiros. Se, na época do capitalismo industrial, o burocrata ideal era examinado apenas como protetor [охранитель, okhranitel'] das condições formais de circulação, agora se demanda um funcionário-organizador, capaz de realizar aquelas tarefas econômicas que, da maneira mais estreita possível, fundem-se com as políticas. Daí a racionalização da burocracia, a infusão no aparato estatal de um novo espírito comercial.

Na opinião do teórico, um conhecido grau de burocratismo na sociedade burguesa às vezes é vantajoso para os proprietários particulares, uma vez que ele inibe a criação legislativa (a de questões sociais, por exemplo) que possa infligir algum dano às classes abastadas. Por outro lado, os proprietários colocam frente ao aparato estatal a demanda de uma menor intervenção, menor regulação, etc. Os ideólogos do Estado e da sociedade burgueses, nota Pachukanis, 
chegam a, com satisfação, afirmar que a lentidão dos procedimentos parlamentares e administrativos é a garantia da estabilidade da sociedade e portanto se apresenta como o maior bem possível (PACHUKANIS, 1930a, p. 11).

Pachukanis volta sua atenção ao contraste disseminado até o momento da revolução entre "público" e "burocratismo", que é ligado à luta entre duas concepções acerca das qualidades que deveriam diferenciar os funcionários públicos [чиновник, tchinovnik]. A demanda dos liberais de substituir a administração burocrática pela atividade independente pública demonstrou o desejo de passar do burocratismo da época do capital comercial e do semifeudalismo à burocracia da época do capital industrial. Isso se manifestou claramente durante a Revolução de Fevereiro, quando os advogados, jurados, procuradores e outros representantes do público [общественность, obshchestvennost'] "de repente encontraram-se em todos os postos resolutamente burocráticos, desde as chancelarias ministeriais até as organizações milicianas" (PACHUKANIS, 1930a, p. 9).

O jurista assinala que não se pode suplantar a característica histórica e de classe do burocratismo por sua caracterização técnica e psicológica, tal como o fazem os pesquisadores burgueses, para os quais o "burocratismo" é uma categoria eterna. O burocratismo para Pachukanis é uma "propriedade inevitável de um aparato apartado das massas e a elas contraposto" (PACHUKANIS, 1934, p. 3).

Seguindo Lenin, ele afirma que o problema da transição do capitalismo ao socialismo está indissoluvelmente ligado ao problema da descoberta de uma nova forma de democracia, de um novo tipo de Estado, que pertenceria a uma estrutura de classe que se alterou e que poderia se tornar um instrumento para transformações político-sociais sem precedentes. Pachukanis considera que destruir o burocratismo não significa destruir o Estado: isso significa formar "um Estado sem distorções burocráticas". As principais características de qualquer Estado são a repressão [подавление, podavlenie] e a coerção que uma classe aplica em relação a outra. Essas funções são mantidas na ditadura do proletariado. Além disso, o aparato que executa essas funções torna-se excepcionalmente poderoso, na medida em que ele joga nes- 
sa luta um papel fundamentalmente essencial [самая существенная роль, samaya sushchestvennaya rol'], na medida em que amplas e maiores massas de trabalhadores se inserem nesse aparato e tomam parte na administração do Estado e na organização da produção. O teórico insiste que a economia planificada pode se dar de uma forma não burocrática, que o Estado pode executar funções repressivas sem perder o seu "caráter antiburocrático" (PACHUKANIS, 1930a, p. 50).

No período de transição ao socialismo, a superação do burocratismo torna-se parte da luta de classes. Além disso, a característica distintiva da luta contra o burocratismo não consiste apenas no desejo de melhorar o aparato de administração (negação dos privilégios e das injustiças, simplificação, redução dos gastos do aparato estatal. etc.), mas também na mudança de seus fins e funções em oposição àqueles que ele defendia na sociedade de classes (PACHUKANIS, 1929, p. 5). Pachukanis critica a Bukharin, que, em sua opinião, cai em um erro teórico ao ver a fonte do burocratismo na economia centralizada socialista (PACHUKANIS, 1934, p. 5).

Pachukanis considera que na economia estatal deve se instalar uma correlação correta entre hierarquia, centralização e autonomia, entre interesse pessoal e dever público [служебный долг, slujebnyi dolg], entre regulamentação e livre-iniciativa, etc. Além disso, não se permite uma ordem tal que, diante dela, a questão da administração encontre-se nas mãos de uma casta privilegiada selecionada e na qual as massas não possam se inserir (PACHUKANIS, 1930, p. 54-55). Ele enfatiza que a fundamental distinção entre o Estado proletário e o burguês é a de que o "direito" nos limites da ditadura proletária defende os interesses da maioria trabalhadora e é direcionado à repressão dos elementos de classe inimigos do proletariado" (PACHUKANIS, 1932, p. 26-27).

O sistema soviético, na opinião de Pachukanis, desdobra todas essas possibilidades que estão contidas dentro de si. Ele volta sua atenção à consideração de que é muito importante não se limitar às promoções [dentro do quadro da administração soviética] apenas dos mais desenvolvidos, habilidosos e dignos representantes isolados da classe trabaIhadora, mas "atrair sem exceção a toda a massa [...] de fato, o Estado 
soviético deve envolver na questão da administração precisamente os mais atrasados, os mais ignorantes, os mais acanhados, para os desenvolver, para levantar suas capacidades" (PACHUKANIS, 1929, p. 19-20).

Pachukanis admoesta sobre a burocratização dos soviets, dos sindicatos e de outras associações públicas de cidadãos. Em particular, ele se manifesta "contra a 'juridicização' dos soviets, contra o enquadramento [изображение, izobrajenie] dos soviets em uma 'forma jurídica' da ditadura do proletariado, porque [...] os soviets não são instituições apenas juridicamente formuladas: eles são uma forma organizacional criada pela atividade criativa [творчество, tvortchestvo] de muitos miIhões das massas e que os congrega no trabalho estatal" (PACHUKANIS, 1932, p. 33). Essa é precisamente a particularidade dos soviets que, na opinião de Pachukanis, permite a eles conduzir as reformas necessárias sem burocratismo. E, se no Estado burguês a máquina estatal tem uma multiplicidade de meios hábeis de afastar as massas da participação na administração, os soviets, por outro lado, garantem às amplas massas de trabalhadores a possibilidade de administrar o Estado (PACHUKANIS, 1930b, p. 169-170).

As ideias de E. Pachukanis sobre o burocratismo e sobre os requisitos de sua superação são valiosos, antes de tudo, porque nelas, em primeiro lugar, volta sua atenção para o caráter de classe desse fenômeno e, em segundo lugar, o jurista soviético nos propicia uma análise histórico-concreta da burocratização do aparato estatal especificamente na sociedade capitalista, que se baseia na compreensão das leis de desenvolvimento do capitalismo mesmo. Além disso, também se mantém atual o seu entendimento acerca das condições necessárias para a "remoção" do burocratismo -- marxista em sua própria essência -- diante da transição à vida comunitária [общежитие, obshchejitie] socialista.

\section{REFERÊNCIAS BIBLIOGRÁFICAS}

BONDARENKO, A. V. Судебная система в CССР в условиях НЭПа [Sistema judicial na URSS sob as condições da NEP]. Resumo da 
dissertação elaborada para a obtenção do título de Kandidat em Ciências Jurídicas. Moscou, 2010, 20 p.

BOWRING, Bill. The antinomies of Yevgeny Pashukanis. Disponível em: <goo.gl/UMav76>. Data de acesso: 28 set. 2016, [2006].

HEAD, Michael. Evgeny Pashukanis: a critical reappraisal. Londres: Routledge-Cavendish, 2008 (Nomikoi: Critical Legal Thinkers).

KHOTCHOYAN, A. G. Основные направления право понимания в советской юридической науке 20-30 гг. [Caminhos fundamentais da compreensão do direito na ciência jurídica soviética dos anos 20-30]. Dissertação para a obtenção do título de Kandidat em Ciências Jurídicas. Samara, 2008, 210 pp.

PACHUKANIS, Evgeniy Bronislavovitch. Советский государственный аппарат и борьба с бюрократизмом [O aparato estatal soviético e a luta contra o burocratismo]. In: ; IGNAT, S. Очередные задачи борьбы с бюрократизмом: Доклады в Институте советского строительства и прения по докладам [As próximas tarefas da luta contra o burocratismo: relatórios ao Instituto de Construção Soviética e debates de acordo com os relatórios]. Moscou: Изд. КомАкадемии, 1929.

Ленин и борьба с бюрократизмом [Lenin e a luta contra o burocratismo]. In: Из ленинского наследия: сборник статей [Do legado leninista: compilação de artigos]. Moscou: Госиздат РСФСР Московский рабочий, 1930а.

. Диктатура пролетариата и современный ревизионизм [A ditadura do proletariado e o revisionismo moderno]. Moscou: Изд. КомАкадемии, 1930b.

Пролетарское государство и построение бесклассового общества [O Estado proletário e a construção de uma sociedade sem classes]. Moscou: [s.e.], 1932.

. Реконструкция госаппарата и борьба с бюрократизмом: тезисы доклада к научной сессии ИССП [A reconstrução do aparato 
estatal e a luta contra o burocratismo: teses ao relatório para a sessão científica do ISSP]. Moscou: [s.e.], 1934.

. Общая теория права и марксизм [Teoria geral do direito e marxismo]. Em: . Избранные Произведения по Общей Теории Права и Государства [Obras escolhidas para uma teoria geral do direito e do Estado]. Моscou: Наука, 1980.

PETUKHOVA, A. V. Меновая концепция Пашуканиса E.Б. [Concepção da troca de mercadorias de E. B. Pachukanis]. In: SHMELEV, K. V. Материалы Международной научно-практической конференции «Опыт регулирования фринансовых отношений в России: историясовременность- перспективы развития» [Materiais da Conferência Internacional prático-científica "Experiência de regulação das relações financeiras na Rússia: história - modernidade - perspectivas de desenvolvimento"]. Nijniy Novgorod: Нижегородский фрилиал ИБП, 2012.

PROTOPOPOV, E. Е. Политико-правовые взгляды Е. Б. Пашуканиса [Opiniões político-jurídicas de E. B. Pachukanis]. Dissertação para a obtenção do título de Kandidat em Ciências Jurídicas. Moscou, 2007, $144 \mathrm{pp}$.

SOLOMKO, Z. V. Раннесовесткая марксистская теория права в контексте современной политико-правовой мысли [Teoria marxista do direito do período soviético inicial no contexto do pensamento político-jurídico moderno]. Ученые записки РГСУ, [s.І.], n. 5, 2011.

TIKHONOVSKIY, F. I. Понимание права в советской юридической науке: 1917-1938 гг. [Compreensão do direito na ciência jurídica soviética: 1917-1938]. Dissertação para a obtenção do título de Kandidat em Ciências Jurídicas, 87 p.

Recebido: 1\%5/2016 Aceito: 15/06/2016 